\title{
Activation of nucleus accumbens NMDA receptors differentially affects appetitive or aversive taste learning and memory
}

\author{
Luis Núñez-Jaramillo ${ }^{1}$, José A. Rangel-Hernández ${ }^{2}$, Belén Burgueño-Zúñiga ${ }^{2}$ \\ and María I. Miranda ${ }^{2}$ * \\ ${ }^{1}$ División de Ciencias de la Salud, Universidad de Quintana Roo, Chetumal, Quintana Roo, México \\ ${ }^{2}$ Departamento de Neurobiología Conductual y Cognitiva, Instituto de Neurobiología, Universidad Nacional Autónoma de México, Juriquilla, Querétaro, México
}

Edited by:
Antonella Gasbarri, University of
I'Aquila, Italy
Reviewed by:
Nashaat Z. Gerges, Medical College
of Wisconsin, USA
Christa Mclntyre, University of
Texas, USA
Patrizia Campolongo, Università degli
Studi di Roma La Sapienza, Italy
Ingo Willuhn, University of
Washington, USA
*Correspondence:
María I. Miranda, Departamento
de Neurobiología Conductual y
Cognitiva, Instituto de Neurobiología,
Universidad Nacional Autónoma de
México, Boulevard Juriquilla No. 3001,
A.P. 1-1141, Juriquilla, Querétaro,
Querétaro 76230, México.
e-mail: mirandami@unam.mx

Taste memory depends on motivational and post-ingestional consequences; thus, it can be aversive (e.g., conditioned taste aversion, CTA) if a novel, palatable taste is paired with visceral malaise, or it can be appetitive if no intoxication appears after novel taste consumption, and a taste preference is developed. The nucleus accumbens (NAc) plays a role in hedonic reactivity to taste stimuli, and recent findings suggest that reward and aversion are differentially encoded by the activity of NAc neurons. The present study examined whether the requirement for $N$-methyl-D-aspartate (NMDA) receptors in the NAc core during rewarding appetitive taste learning differs from that during aversive taste conditioning, as well as during retrieval of appetitive vs. aversive taste memory, using the taste preference or CTA model, respectively. Bilateral infusions of NMDA $(1 \mu \mathrm{g} / \mu \mathrm{l}, 0.5 \mu \mathrm{l})$ into the NAc core were performed before acquisition or before retrieval of taste preference or CTA. Activation of NMDA receptors before taste preference training or CTA acquisition did not alter memory formation. Furthermore, NMDA injections before aversive taste retrieval had no effect on taste memory; however, $24 \mathrm{~h}$ later, CTA extinction was significantly delayed. Also, NMDA injections, made before familiar appetitive memory retrieval, interrupted the development of taste preference and produced a preference delay $24 \mathrm{~h}$ later. These results suggest that memory formation for a novel taste produces neurochemical changes in the NAc core that have differential requirements for NMDA receptors during retrieval of appetitive or aversive memory.

Keywords: glutamate receptor, nucleus accumbens core, taste recognition, taste preference, emotional learning

\section{INTRODUCTION}

The nucleus accumbens (NAc) is a brain region located within the ventral striatum, and its critical role in processing rewardrelated stimuli and instrumental responses is well documented (Salamone, 1996; Corbit et al., 2001; Hall et al., 2001; Holland and Gallagher, 2003; Kelley, 2004a; Pothuizen et al., 2005). On the basis of distinctive anatomical profiles and functional specialization, the NAc has been divided into two subregions: accumbens shell and core, and their associated circuitry has also been proposed (Heimer et al., 1991; Deutch and Cameron, 1992; Zahm and Brog, 1992). Previous research suggests that the accumbens shell functions as a critical link between cortical circuits and hypothalamic/brainstem circuits with regard to the control of food intake, while the accumbens core, and its connected circuitry, is involved in the learning and execution of adaptive instrumental actions (Kelley, 2004b). The NAc participates in the control of behaviors related to natural reinforcers and is well positioned to participate in neural control of food intake, which is also related to processes required during taste memory recognition. Accordingly, the NAc has a major role in the regulation of both reward and aversion during emotional/hedonic reactivity to taste stimuli (Ventura et al., 2007; Roitman et al., 2010).
During taste learning, a taste stimulus is recognized and associated with post-ingestional consequences; an aversive taste memory is formed if intoxication or malaise signals appear, inducing a significant decrease of consumption during the next encounter with that taste. Conversely, if after consumption no intoxication is detected, an appetitive taste memory is formed, and a significant increase of consumption is induced if the taste is palatable (Núñez-Jaramillo et al., 2010). Therefore, taste learning can alter the hedonic valence of a given stimulus, and evidence suggests that the NAc has an important role during this hedonic shift (Roitman et al., 2010). Accordingly, significant changes in the release of several neurotransmitters, in both NAc subregions, have been described during learning of conditioned taste aversion (CTA; Mark et al., 1991; Hajnal and Norgren, 2001), and an increase in the expression of $c$-fos during CTA retrieval (Yasoshima et al., 2006) has also been reported. Consistent with these reports, there is evidence indicating that dopaminergic receptors in the NAc play a crucial role in regulating cell activity during reward and aversion codification of different stimuli (Carlezon Jr. and Thomas, 2009). Moreover, consumption of sucrose induces a decrease in neuronal activity, but aversively conditioned sucrose consumption induces an increase in the activity of NAc neurons (Roitman et al., 2010). 
In particular, pharmacological studies have demonstrated that the NAc is needed during CTA taste memory acquisition and/or consolidation (Ramirez-Lugo et al., 2006; Yamamoto, 2007; Pedroza-Llinas etal., 2009) and that the N-methyl-Daspartate (NMDA) receptors in the NAc have a modulatory role during appetitive extinction (Holahan et al., 2012). Currently, the evidence indicates that NMDA receptors in the NAc have diverse functions during some stages of taste memory formation; it has been reported that blockade of NMDA receptors in both NAc subregions impairs CTA acquisition, but this effect is stronger with NAc core NMDA blockade. Moreover, infusion of NMDA into either of the NAc subregions had no effect on attenuation of neophobia (Ramirez-Lugo et al., 2006). Taken together, the evidence suggests that NMDA receptors in the NAc have an important function during reward and/or aversive taste stimulus processing, possibly by modulating NAc dopaminergic activity (Howland et al., 2002) and interacting with other brain structures (Bermudez-Rattoni, 2004; Núñez-Jaramillo et al., 2010).

Despite such evidence, there is little information that directly compares the function of NMDA receptors in the NAc core during appetitive taste learning vs. during aversive taste conditioning, i.e., comparing their role in the different taste emotional/hedonic reactivity induced during and after learning. Thus, the present study, using the same taste stimulus in a preference protocol or CTA model, examined the requirement for NMDA receptors in the NAc core during appetitive taste learning or during CTA acquisition, and the role of these receptors during retrieval of appetitive or aversive taste memory.

\section{EXPERIMENTAL PROCEDURES ANIMALS}

Ninety-one male Wistar rats (Instituto de Neurobiología breeding colony, Mexico; 250-300 $\mathrm{g}$ at time of surgery) were used. Rats were housed individually and maintained at $23^{\circ} \mathrm{C}$ under an inverted, 12-h/12-h light-dark cycle (lights off from 9:00 a.m. to 9:00 p.m.). All behavioral protocols were implemented during the dark portion of the cycle. Food and water were available ad libitum until the behavioral procedures began. Experiments were performed in accordance with the Rules in Health Matters (Ministry of Health, Mexico) and with the approval of the local Animal Care Committee.

\section{SURGERY}

All animals were anesthetized with ketamine $(70 \mathrm{mg} / \mathrm{kg})$ and xylazine $(6 \mathrm{mg} / \mathrm{kg})$ i.p. and implanted bilaterally with $12-\mathrm{mm}, 23-$ gauge, stainless-steel cannulae aimed $2 \mathrm{~mm}$ above the NAc core (antero-posterior $+1.5 \mathrm{~mm}$, lateral $\pm 1.9 \mathrm{~mm}$, ventral $-4.7 \mathrm{~mm}$ from Bregma) according to Paxinos and Watson (1998). Cannulae were fixed to the skull with dental acrylic cement and anchored with two surgical screws placed in the skull. Stylets were inserted into the cannulae to prevent clogging. One week after surgery, animals were deprived of water for $12 \mathrm{~h}$. The animals were then acclimated to the deprivation regimen for 7 days, with access to water in their home cage for $20 \mathrm{~min}$ each day between 12:00 and 14:00 h.

\section{BEHAVIORAL PROCEDURES}

Conditioned taste aversion

One week after surgery, the animals for the CTA experiment were water deprived and began a regime in which they had access to water from a graduated bottle for $20 \mathrm{~min}$ each day to establish basal water consumption. After 5 days of baseline water consumption, the CTA acquisition was implemented; animals had access to a novel $0.1 \%$ saccharin solution for $20 \mathrm{~min}$, and $30 \mathrm{~min}$ later they were injected i.p. with lithium chloride $(0.25 \mathrm{M} \mathrm{LiCl}, 10 \mathrm{ml} / \mathrm{kg})$, a malaise-inducing drug (Figure 1A, S1). The next day, during the memory retrieval test, all rats were again exposed only to $0.1 \%$ saccharin for $20 \mathrm{~min}$ in order to evaluate the taste aversion (Figure 1A, S2). The reduction of saccharin consumption during the retrieval compared with saccharin consumption during the acquisition was used as a measure of CTA strength. Over the next 2 days, rats were again exposed to saccharin to establish extinction of CTA (Figure 1A, S3,S4). For data analysis, saccharin consumption during retrieval and extinction is presented as percentage of saccharin consumption during acquisition (ACQ), using the formula: $\%$ of $\mathrm{ACQ}=($ milliliter of saccharin consumed during retrieval or extinction $\times 100) /$ milliliter of saccharin consumed during acquisition.

\section{Taste preference}

One week after surgery, animals were deprived of water and began a regime in which they had access to water from two graduated bottles for 20 min each day to establish basal water consumption. Bottles were placed on opposite sides of one of the narrow sides of the home cage and were rotated every $2.5 \mathrm{~min}$. After 5 days of baseline water consumption, animals began the taste preference procedure. On the acquisition day, rats had access to one bottle of water and one bottle of novel $0.1 \%$ saccharin; the bottles were rotated every $2.5 \mathrm{~min}$ to avoid an attachment by the rat to a single bottle (Figure 1B, S1). The following day and $72 \mathrm{~h}$ later, the rats were again exposed to saccharin, with the same protocol, to evaluate the development of taste preference (i.e., appetitive taste memory retrieval; Figure 1B, S2,S3). Saccharin consumption is presented as a percent of the total amount of fluid consumed that day, calculated by the formula: $\% \mathrm{Sac}=$ $($ milliliter of saccharin $\times 100) /($ milliliter of saccharin + milliliter of water).

\section{DRUGS AND INFUSION PROCEDURES}

Two days before infusion, all animals were handled individually for approximately $5 \mathrm{~min}$ every $24 \mathrm{~h}$. On infusion day, a total volume of $0.5 \mu \mathrm{l}$ of NMDA (SIGMA, Mexico; $1 \mu \mathrm{g} / \mu \mathrm{l}$ dissolved in sterile $0.9 \%$ saline) or $0.9 \%$ saline was infused bilaterally into the NAc core, through 30-gauge injection needles connected to $10-\mu 1$ Hamilton microsyringes by polyethylene tubing. Using an automated syringe pump (Sage Instruments), $0.5 \mu \mathrm{l}$ of solution was infused bilaterally over $60 \mathrm{~s}$, and the injection needle was kept in place for an additional $60 \mathrm{~s}$ to allow diffusion of the solution into the tissue and to minimize dragging back along the injection track. Independent groups were infused in the NAc 20 min before novel taste presentation (acquisition, Figures 1A,B, S1), or $20 \mathrm{~min}$ before the second saccharin presentation of CTA or taste preference (memory retrieval test, Figures 1A,B, S2). 


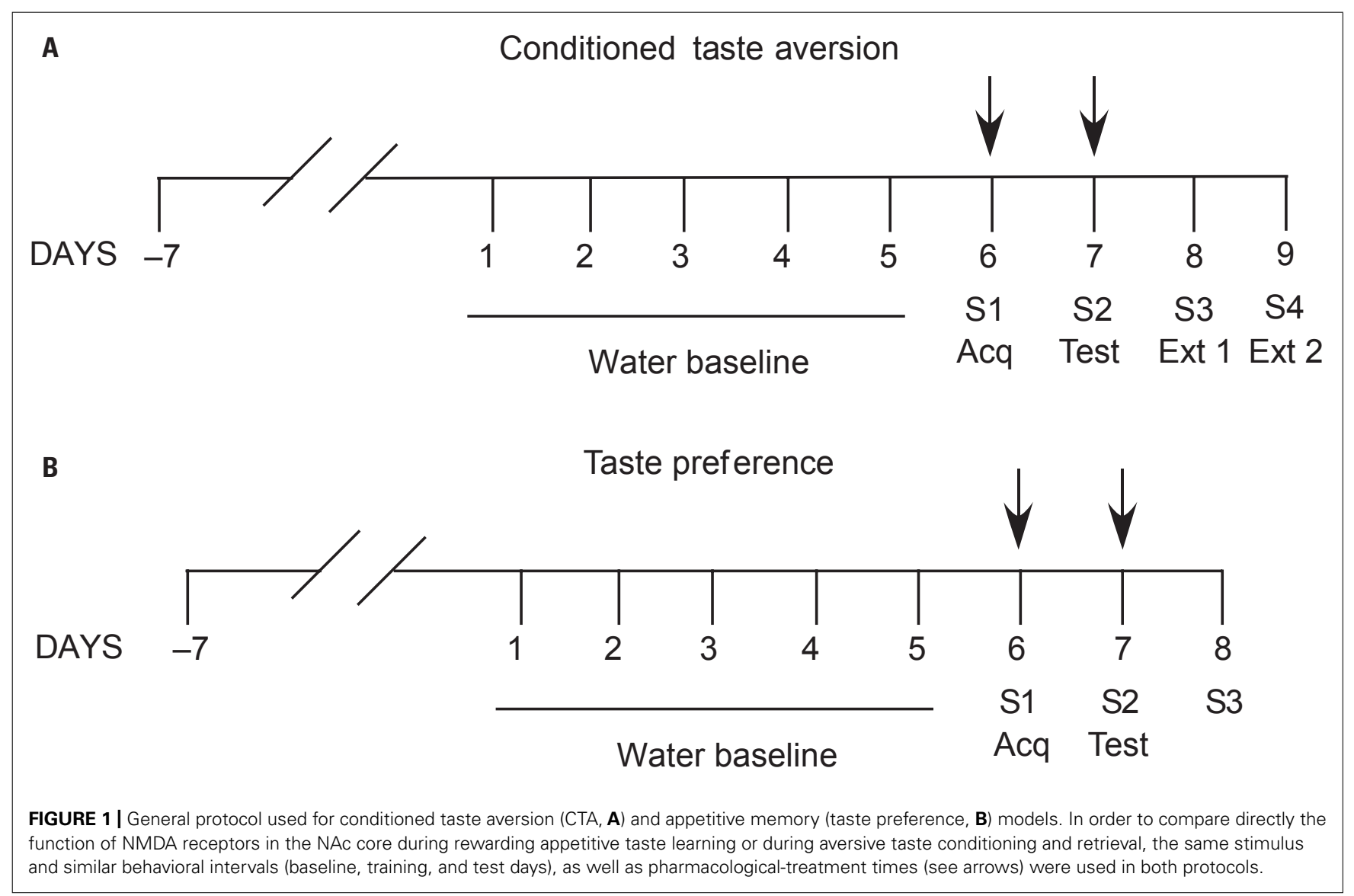

\section{HISTOLOGY}

At the end of behavioral experiments, animals were overdosed with sodium pentobarbital and perfused transcardially with $0.9 \%$ saline. The brains were removed and stored at $4^{\circ} \mathrm{C}$ in a $4 \%$ paraformaldehyde solution for $24 \mathrm{~h}$. Brains were then floated in $30 \%$ glucose solution and stored at $4^{\circ} \mathrm{C}$ until they sank. Coronal sections ( $50 \mu \mathrm{m}$ thick) were cut through the area of interest. The sections were stained with cresyl violet and examined microscopically to determine cannula placement (Figure 2). Data from animals with misplaced cannulae $(n=14)$ were excluded from the statistical analysis.

\section{STATISTICAL ANALYSIS}

In order to determine in CTA experiments, whether animals presented a change in saccharin consumption, between groups and among the 4 days of taste exposure, a repeated-measure ANOVA was performed; using the percentage of acquisition consumption $[\%$ of $\mathrm{ACQ}=$ (milliliter of saccharin consumed during retrieval or extinction $\times 100) /$ milliliter of saccharin consumed during acquisition], followed by post hoc Bonferroni/Dunn tests, where appropriate. Similarly, in the taste preference groups, a repeated-measure ANOVA was performed with the total amount of fluid consumed each day $[\% \mathrm{Sac}=$ (milliliter of saccharin $\times 100) /($ milliliter of saccharin + milliliter of water)]; followed by post hoc Bonferroni/Dunn tests, where appropriate.

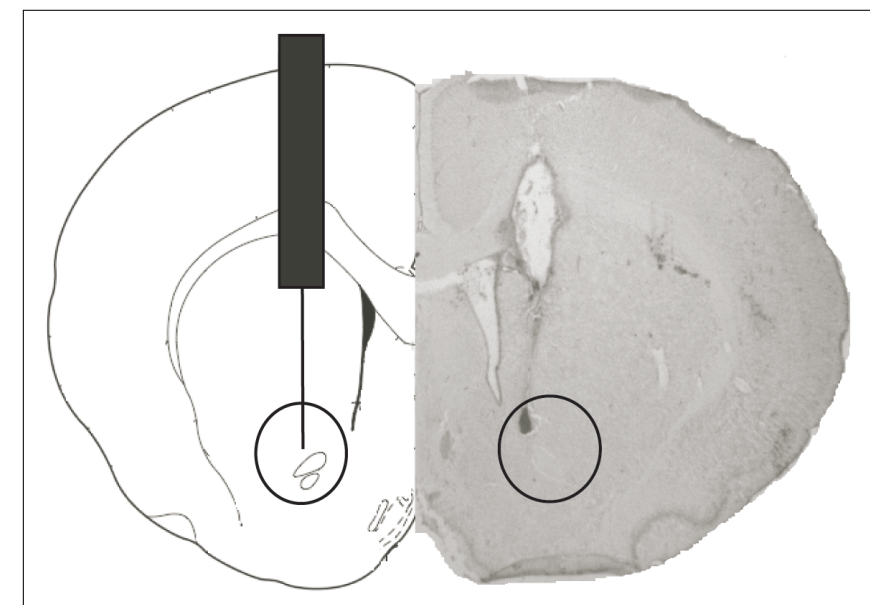

FIGURE 2 | Microphotography and diagram of coronal section of rat brain showing the area of the injection site in the NAc core.

\section{RESULTS}

NMDA RECEPTOR ACTIVATION IN THE NAC CORE BEFORE CTA ACQUISITION DOES NOT AFFECT CTA MEMORY FORMATION OR EXTINCTION

In order to evaluate the effects of NMDA receptor activation in the NAc core during CTA acquisition and/or consolidation, infusions 
of NMDA were made before the first presentation of saccharin (Figure 3A). Repeated-measures ANOVA of percentage saccharin acquisition consumption, showed no significant differences between treatments (Saline and NMDA) groups $\left(F_{1,22}=1.25\right.$, $p>0.05)$ but revealed significant differences between treatment days (ACQ, TEST, EXT 1, and EXT 2; $F_{1,22}=19.03, p<0.01$ ); not significant interaction $\left(F_{1,22}=1.09, p>0.05\right)$. Post hoc analysis showed significant differences between ACQ and TEST $(p<0.01)$, as well as between TEST and EXT $2(p<0.05)$ for both Saline and NMDA groups. All animals consumed similar amounts of water during baseline (data not shown). During acquisition, both Saline- $(n=10)$ and NMDA- $(n=13)$ infused groups consumed a similar amount of saccharin $(11.2 \pm 1.35 \mathrm{ml}$ Saline and $11.69 \pm 0.73 \mathrm{ml} \mathrm{NMDA}$ ). As shown in Figure 3A, animals consumed similar percentages of saccharin during retrieval $(39.4 \pm 7.09 \%$ Saline and $43.45 \pm 6.87 \%$ NMDA $)$, as well as during the first $(64.45 \pm 7.72 \%$ Saline and $66.19 \pm 8.14 \%$ NMDA $)$ and second ( $108.15 \pm 23.43 \%$ Saline and $81.13 \pm 8.76 \%$ NMDA) extinction trials.

\section{NMDA RECEPTOR ACTIVATION IN THE NAC CORE BEFORE RETRIEVAL PRODUCES A DELAY IN CTA MEMORY EXTINCTION}

In order to evaluate the effects of NMDA receptor activation in the NAc core during aversive taste retrieval and during the extinction process, in an independent group, NMDA infusions were made before CTA test (Figure 3B). Repeated-measures ANOVA of percentage saccharin acquisition consumption showed significant differences between groups $\left(F_{1,22}=4.51, p=0.04\right)$ and significant differences between treatment days (ACQ, TEST, EXT 1, and
EXT 2) $\left(F_{1,22}=40.90, p<0.01\right)$; but not significant interaction $\left(F_{1,22}=1.76, p>0.05\right)$. Post hoc analysis showed significant differences between ACQ and TEST $(p<0.01)$, as well as between TEST and EXT $2(p<0.01)$ for both Saline and NMDA groups. As expected, all animals consumed similar amounts of saccharin during acquisition (Saline group, $12 \pm 1.04 \mathrm{ml}, n=12$; NMDA group, $13.08 \pm 1.12 \mathrm{ml}, n=12)$, and drank similar amounts of saccharin during retrieval (Saline, $27.95 \pm 5.07 \%$; NMDA, $21.97 \pm 4.85 \%$ ). However, during the first extinction trial (EXT 1), post hoc analyses showed significant differences between Saline and NMDA groups $(p<0.05)$. The NMDAinfused group showed significantly lower saccharin consumption $(44.32 \pm 7.83 \%)$ than the Saline-infused group $(75.62 \pm 9.63 \%)$. During the second extinction trial, both groups again consumed similar amounts of saccharin (Saline, $94.89 \pm 12.4 \%$; NMDA, $78.4 \pm 11.17 \%)$.

\section{NMDA RECEPTOR ACTIVATION IN THE NAC CORE BEFORE FIRST SACCHARIN CONSUMPTION DOES NOT ALTER THE DEVELOPMENT OF TASTE PREFERENCE}

In order to evaluate the effect of NMDA receptor activation in the NAc core on appetitive taste memory formation, infusions were made before the first saccharin consumption during the taste preference protocol (Figure 4A). All animals had similar baseline water consumption (data not shown). Repeated-measures ANOVA of percentage saccharin consumption showed no significant differences between groups $\left(F_{1,22}=0.081, p>0.05\right)$ but revealed significant differences between treatment days (S1-S3; $\left.F_{1,22}=6.574, p<0.01\right)$; there was also a tendency to interaction

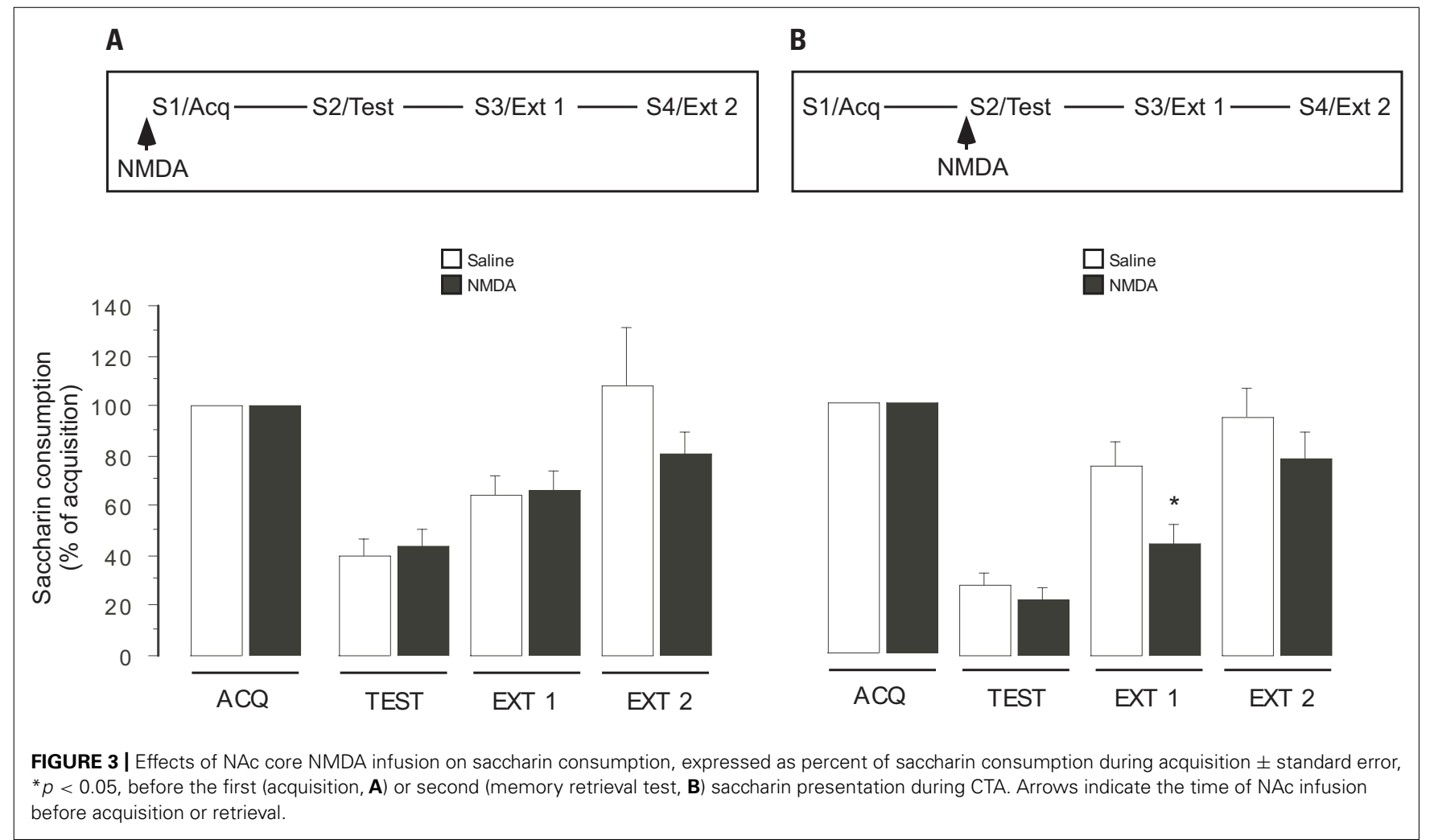


A

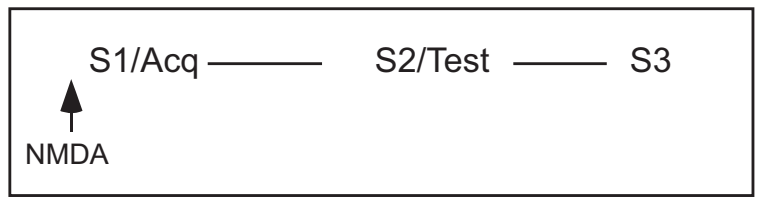

$\square$ Saline
$\square$ NMDA

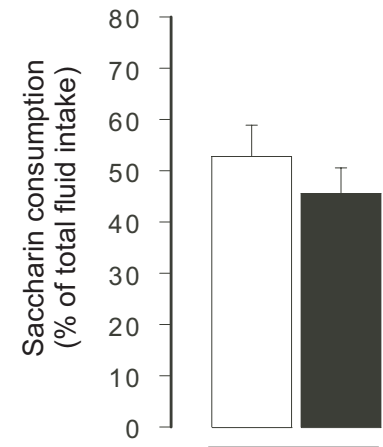

Sac 1

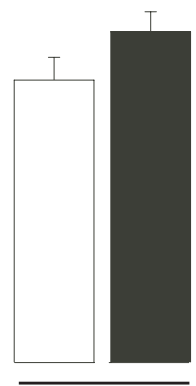

Sac 2

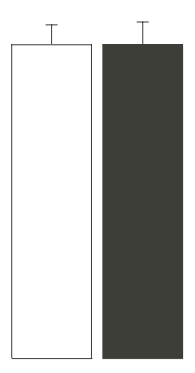

Sac 3
FIGURE 4 | Effects of NAc core NMDA infusion on saccharin consumption before the first (acquisition, A) or second (memory retrieval test, B) saccharin presentation during taste preference. Bars represents saccharin consumption
B

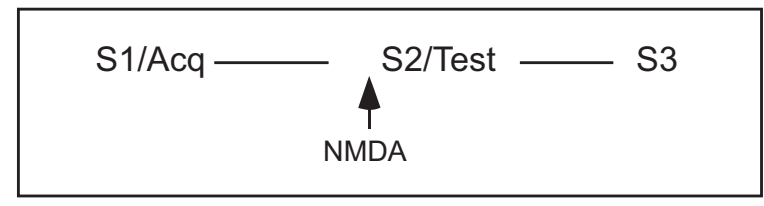

$\square$ Saline
$\square$ NMDA

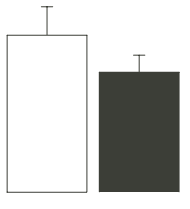

Sac 1

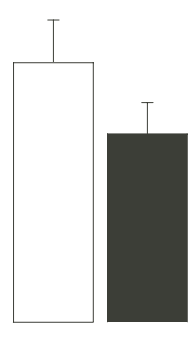

Sac 2

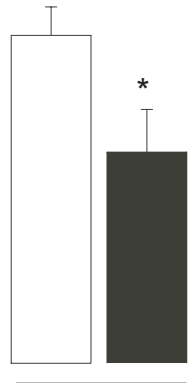

Sac 3 on each day, as percent of total fluid intake \pm standard error, ${ }^{*} p<0.05$ Arrows at the top indicate the time of NAc infusion before acquisition or retrieval.
$\left(F_{1,22}=2.78, p=0.07\right)$. Post hoc analysis revealed that saccharin consumption changed significantly over the 3 days of saccharin exposure in the NMDA-infused group (S1-S3; $p<0.05)$, but not in the Saline-infused group $(p>0.05)$. Nevertheless, both the Saline- $(n=11)$ and NMDA- $(n=11)$ infused animals consumed comparable amounts of saccharin during the first (52.65 $\pm 6 \%$ Saline group and $45.3 \pm 5.25 \%$ NMDA group), second (54.86 $\pm 4.46 \%$ Saline and $64.2 \pm 3.86 \%$ NMDA), and third $(61.24 \pm 3.7 \%$ Saline and $60.96 \pm 4.48 \%$ NMDA $)$ saccharin presentation (Figure 4A).

\section{NMDA RECEPTOR ACTIVATION IN THE NAC CORE BEFORE SECOND SACCHARIN CONSUMPTION DISRUPTS TASTE PREFERENCE}

To evaluate the effect of NMDA receptor activation in the NAc core during retrieval of appetitive taste memory, infusions were done before the second saccharin presentation during the taste preference protocol (Figure 4B). All animals consumed similar amounts during baseline water consumption (data not shown). During the first saccharin consumption, animals of the Saline- $(n=11)$ and NMDA- $(n=11)$ infusion groups consumed similar amounts of saccharin $(30.52 \pm 5.5 \%$ Saline and $23.3 \pm 3.18 \%$ NMDA; Figure 4B). Repeated-measures ANOVA of the percentage saccharin consumption showed significant differences between groups $\left(F_{1,22}=5.156, p<0.05\right)$ and also revealed significant differences between treatment days (S1-S3; $\left.F_{1,22}=11.54, p<0.01\right)$. Saccharin consumption increased significantly over the 3 days of saccharin exposure (S1-S3) in the Saline-infused animals $(p<0.01)$, but not in the NMDAinfused animals $(p>0.05)$. Post hoc test revealed no significant difference between groups during first saccharin consumption, either significant difference between groups during second day consumption $(p=0.07 ; 50.62 \pm 8.08 \%$ Saline and $36.55 \%$ NMDA). During the third saccharin exposure the NMDA-infused group had significantly $(p<0.05)$ lower saccharin consumption $(41.13 \pm 8.36 \%)$ than the Saline-infused group $(63.95 \pm 5.62 \%$; Figure 4B).

\section{DISCUSSION}

The present results demonstrated that NMDA receptor activation in the NAc core has differential effects on taste memory formation and retrieval, depending on whether an appetitive or aversive memory is formed. NMDA receptor activation before acquisition of aversive taste memory had no effect on memory formation. Moreover, NMDA receptor activation before aversive memory left retrieval intact, but significantly delayed the extinction of taste aversion (Figure 3). The results also showed that the NAc core is a sensitive structure during taste preference acquisition, since saline infusion during acquisition did influence taste consumption, compared with the experimental group that received saline infusion during retrieval, or compared with an intact animals (data not shown), that consumed approximately $30 \%$ less saccharin during the first day of the taste preference protocol. Despite this effect, the total volume of saccharin consumed during the first presentation did not differ between groups infused either with saline or NMDA. Moreover, the saline infusion before 
the first saccharin consumption did not impair the formation of an appetitive taste memory, since animals consumed a large amount of saccharin during the second exposure to saccharin, compared with the intact group or with the group infused with saline during retrieval (see Figure 4B). These data suggest that saline infusion into the NAc core before the first saccharin consumption did not affect either taste perception or the formation of taste appetitive memory; possibly, it altered drink motivation or the ability to detect saliency between stimuli (e.g., water vs. saccharin). In this regard, previous evidence showed that blockade of NMDA receptors induces deficits in signaling processes that participate in termination of satiety signals (Burns and Ritter, 1997), and inhibition of some NAc regions changes the positive hedonic responses to palatable taste solutions (Pecina and Berridge, 2005). Furthermore, the data obtained during CTA acquisition corroborates this idea, because saline or NMDA infusions, made before the first saccharine consumption, had no effect on taste memory formation, which requires an intact taste perception. Further studies are needed to understand the NAc core involvement during processing of relevant properties in the first taste encounter.

Our results also show that NMDA receptor function differs between acquisition and retrieval of taste appetitive memory, since NMDA receptor activation before memory retrieval significantly delayed the development of taste preference after the second saccharin consumption (Figure 4B). Previously, it was reported that blockade of NMDA receptors in the NAc does not affect attenuation of neophobia, another model of appetitive taste memory (Ramirez-Lugo et al., 2006). However, there are important differences between attenuation of neophobia and the taste preference protocol; during attenuation of neophobia only one bottle was presented, while in taste preference, subjects were able to choose between saccharin and water. Another difference is that the saccharin concentration used in the attenuation of neophobia $(0.5 \%)$ was greater than the concentration used in the current taste preference task $(0.1 \%)$.

As mentioned earlier, since taste memory formation depends on motivational and post-ingestional consequences, the memory formed after novel taste consumption can be associated with a positive reward, or with an aversive consequence, as observed during CTA (Bermudez-Rattoni, 2004; Núñez-Jaramillo et al., 2010). Consequently, taste learning can alter the hedonic valence of a given stimulus (Gutierrez et al., 2003; Bermudez-Rattoni, 2004), which could be related to the evidence that NAc has a role in the assignment of hedonic value of stimuli, either positive or negative (Ventura et al., 2007; Roitman et al., 2010). Accordingly, it could be argued that NMDA receptor activation, before retrieval of either appetitive or aversive taste memory, increases the negative hedonic value of the previous taste memory representation. In line with this, our results demonstrate that consumption of familiar saccharin (third presentation), either appetitive or aversive, significantly decreases after NMDA activation, diminishing preference or extinction.

The present data could be also related to electrophysiological findings that consumption of palatable food stimuli is associated with decreases in the firing rate of the majority of responsive NAc neurons (Nicola et al., 2004; Roitman et al., 2005; Taha and
Fields, 2005; Wheeler et al., 2008) and that the activity of NAc cells decreases during rewarding stimulus presentation and increases in the presence of aversive stimulus (Carlezon Jr. and Thomas, 2009; Roitman et al., 2010). We found that NMDA receptor activation correlates mainly with retrieval or memory processing of familiar appetitive or aversive taste. Although NMDA receptor activation did not affect CTA retrieval, it did produce a significant delay in aversive extinction (Figure 3B), indicating that the NAc core has an important role during the process of re-learning an aversive stimulus. Taken together, these results suggest that activation of NAc core NMDA receptors before retrieval of either appetitive or aversive taste memory enhances the aversive value associated with the taste.

The current results suggest that taste learning induces neurochemical changes in the NAc core during memory retrieval and re-learning of the same stimulus; these changes lead to a differential taste processing that is modulated by the glutamatergic system. In this regard, it has been reported that taste learning produces important biochemical changes in various brain structures such as the insular cortex, amygdala, and NAc (Bermudez-Rattoni, 2004; Núñez-Jaramillo et al., 2010). Thus, the differential effect of NMDA receptor activation on taste memory acquisition or retrieval, reported here, might be due to a reorganization of the neurochemical processes in the NAc that occurs as a consequence of taste memory formation. This reorganization could involve changes in the localization of glutamate receptors, as previously reported in other structures (Heynen et al., 2000; Goebel et al., 2005; Núñez-Jaramillo et al., 2008) and modulation of systems using other neurotransmitters, such as dopamine and acetylcholine (Mark et al., 1991, 1995; Howland et al., 2002). Further studies are needed to confirm that memory formation produces plastic changes in the NAc core that induce differential requirements for NMDA receptors during appetitive or aversive taste learning and memory. Our results also give evidence that the NAc core is a sensitive structure during taste appetitive memory formation, since control animals with infusions during the first day of taste preference training did not decrease their saccharin consumption. These data suggest a modulatory role of the NMDA receptors during drink motivation or the ability to detect saliency between stimuli (e.g., water vs. saccharin), that could be observed by the preference (two bottles) protocol used in these experiments.

In conclusion, the present study directly compares the function of NMDA receptors in the NAc core during appetitive taste learning or during aversive taste conditioning. Using the same taste stimulus in a preference protocol or CTA model, we provide evidence of an important regulatory role for NMDA receptors in the NAc core during memory retrieval and re-learning of rewarded or aversive taste.

\section{ACKNOWLEDGMENTS}

This research was supported by DGAPA-PAPIIT IN209911 and CONACyT 152208. We thank Dr. Dorothy Pless and Shaun Harris for the English revision of the final text. We also thank Martín García, Ángela Gabriela Vera-Rivera, Nydia Hernández-Ríos, and Lorena López for their technical assistance. 


\section{REFERENCES}

Bermudez-Rattoni, F. (2004). Molecular mechanisms of taste-recognition memory. Nat. Rev. Neurosci. 5, 209-217.

Burns, G. A., and Ritter, R. C. (1997). The non-competitive NMDA antagonist MK-801 increases food intake in rats. Pharmacol. Biochem. Behav. 56, 145-149.

Carlezon, W. A. Jr., and Thomas, M. J. (2009). Biological substrates of reward and aversion: a nucleus accumbens activity hypothesis. Neuropharmacology 56(Suppl. 1), 122-132.

Corbit, L. H., Muir, J. L., and Balleine, B. W. (2001). The role of the nucleus accumbens in instrumental conditioning: evidence of a functional dissociation between accumbens core and shell. J. Neurosci. 21, 3251-3260.

Deutch, A. Y., and Cameron, D. S. (1992). Pharmacological characterization of dopamine systems in the nucleus accumbens core and shell. Neuroscience 46, 49-56.

Goebel, S. M., Alvestad, R. M., Coultrap, S. J., and Browning, M. D. (2005). Tyrosine phosphorylation of the $N$-methyl-D-aspartate receptor is enhanced in synaptic membrane fractions of the adult rat hippocampus. Brain Res. Mol. Brain Res. 142, 65-79.

Gutierrez, R., Rodriguez-Ortiz, C. J., De La Cruz, V., Núñez-Jaramillo, L., and Bermudez-Rattoni, F. (2003). Cholinergic dependence of taste memory formation: evidence of two distinct processes. Neurobiol. Learn. Mem. 80, 323-331.

Hajnal, A., and Norgren, R. (2001). Accumbens dopamine mechanisms in sucrose intake. Brain Res. 904, 76-84.

Hall, J., Parkinson, J. A., Connor, T. M., Dickinson, A., and Everitt, B. J. (2001). Involvement of the central nucleus of the amygdala and nucleus accumbens core in mediating Pavlovian influences on instrumental behaviour. Eur. J. Neurosci. 13, 1984-1992.

Heimer, L., Zahm, D. S., Churchill, L., Kalivas, P. W., and Wohltmann, C. (1991). Specificity in the projection patterns of accumbal core and shell in the rat. Neuroscience 41, 89-125.
Heynen, A. J., Quinlan, E. M., Bae, D. C., and Bear, M. F. (2000). Bidirectional, activity-dependent regulation of glutamate receptors in the adult hippocampus in vivo. Neuron 28, 527-536.

Holahan, M. R., Westby, E. P., and Albert, K. (2012). Comparison of the MK-801-induced appetitive extinction deficit with pressing for reward and associated $\mathrm{pERK} 1 / 2$ staining in prefrontal cortex and nucleus accumbens. Behav. Brain Res. 228, 194-202.

Holland, P. C., and Gallagher, M. (2003). Double dissociation of the effects of lesions of basolateral and central amygdala on conditioned stimulus-potentiated feeding and Pavlovian-instrumental transfer. Eur. J. Neurosci. 17, 1680-1694.

Howland, J. G., Taepavarapruk, P., and Phillips, A. G. (2002). Glutamate receptor-dependent modulation of dopamine efflux in the nucleus accumbens by basolateral, but not central, nucleus of the amygdala in rats. J. Neurosci. 22, 1137-1145.

Kelley, A. E. (2004a). Memory and addiction: shared neural circuitry and molecular mechanisms. Neuron 44, 161-179.

Kelley, A. E. (2004b). Ventral striatal control of appetitive motivation: role in ingestive behavior and rewardrelated learning. Neurosci. Biobehav. Rev. 27, 765-776.

Mark, G. P., Blander, D. S., and Hoebel, B. G. (1991). A conditioned stimulus decreases extracellular dopamine in the nucleus accumbens after the development of a learned taste aversion. Brain Res. 551, 308-310.

Mark, G. P., Weinberg, J. B., Rada, P. V., and Hoebel, B. G. (1995). Extracellular acetylcholine is increased in the nucleus accumbens following the presentation of an aversively conditioned taste stimulus. Brain Res. 688, 184-188.

Nicola, S. M., Yun, I. A., Wakabayashi, K. T., and Fields, H. L. (2004). Firing of nucleus accumbens neurons during the consummatory phase of a discriminative stimulus task depends on previous reward predictive cues. $J$. Neurophysiol. 91, 1866-1882.

Núñez-Jaramillo, L., Jimenez, B., Ramirez-Munguia, N., DelintRamirez, I., Luna-Illades, C., Tapia,
R., and Bermudez-Rattoni, F. (2008). Taste novelty induces intracellular redistribution of $\mathrm{NR} 2 \mathrm{~A}$ and $\mathrm{NR} 2 \mathrm{~B}$ subunits of NMDA receptor in the insular cortex. Brain Res. 1215, 116-122.

Núñez-Jaramillo, L., Ramirez-Lugo, L. Herrera-Morales, W., and Miranda, M. I. (2010). Taste memory formation: latest advances and challenges. Behav. Brain Res. 207, 232-248.

Paxinos, G., and Watson, C. (1998). The Rat Brain in Stereotaxic Coordinates, 4th Edn. San Diego: Academic Press.

Pecina, S., and Berridge, K. C. (2005). Hedonic hot spot in nucleus accumbens shell: where do muopioids cause increased hedonic impact of sweetness? J. Neurosci. 25, 11777-11786.

Pedroza-Llinas, R., Ramirez-Lugo, L., Guzman-Ramos, K., Zavala-Vega, S., and Bermudez-Rattoni, F. (2009). Safe taste memory consolidation is disrupted by a protein synthesis inhibitor in the nucleus accumbens shell. Neurobiol. Learn. Mem. 92, 45-52.

Pothuizen, H. H., Jongen-Relo, A. L., Feldon, J., and Yee, B. K. (2005). Double dissociation of the effects of selective nucleus accumbens core and shell lesions on impulsive-choice behaviour and salience learning in rats. Eur. J. Neurosci. 22, 2605-2616.

Ramirez-Lugo, L., Zavala-Vega, S., and Bermudez-Rattoni, F. (2006). NMDA and muscarinic receptors of the nucleus accumbens have differential effects on taste memory formation. Learn. Mem. 13, 45-51.

Roitman, M. F., Wheeler, R. A., and Carelli, R. M. (2005). Nucleus accumbens neurons are innately tuned for rewarding and aversive taste stimuli, encode their predictors, and are linked to motor output. Neuron 45 , 587-597.

Roitman, M. F., Wheeler, R. A., Tiesinga, P. H., Roitman, J. D., and Carelli, R. M. (2010). Hedonic and nucleus accumbens neural responses to a natural reward are regulated by aversive conditioning. Learn. Mem. 17, 539-546.

Salamone, J. D. (1996). The behavioral neurochemistry of motivation: methodological and conceptual issues in studies of the dynamic activity of nucleus accumbens dopamine. J. Neurosci. Methods 64, 137-149.
Taha, S. A., and Fields, H. L. (2005). Encoding of palatability and appetitive behaviors by distinct neuronal populations in the nucleus accumbens. J. Neurosci. 25, 1193-1202.

Ventura, R., Morrone, C., and Puglisi-Allegra, S. (2007). Prefrontal/accumbal catecholamine system determines motivational salience attribution to both reward- and aversion-related stimuli. Proc. Natl. Acad. Sci. U.S.A. 104, 5181-5186.

Wheeler, R. A., Twining, R. C., Jones, J. L., Slater, J. M., Grigson, P. S., and Carelli, R. M. (2008). Behavioral and electrophysiological indices of negative affect predict cocaine self-administration. Neuron 57, 774-785.

Yamamoto, T. (2007). Brain regions responsible for the expression of conditioned taste aversion in rats. Chem. Senses 32, 105-109.

Yasoshima, Y., Scott, T. R., and Yamamoto, T. (2006). Memorydependent $\mathrm{c}$-Fos expression in the nucleus accumbens and extended amygdala following the expression of a conditioned taste aversive in the rat. Neuroscience 141, 35-45.

Zahm, D. S., and Brog, J. S. (1992). On the significance of subterritories in the "accumbens" part of the rat ventral striatum. Neuroscience 50 , 751-767.

Conflict of Interest Statement: The authors declare that the research was conducted in the absence of any commercial or financial relationships that could be construed as a potential conflict of interest.

Received: 01 August 2011; accepted: 24 March 2012; published online: 19 April 2012.

Citation: Núñez-Jaramillo L, RangelHernández JA, Burgueño-Zúñiga B and Miranda MI (2012) Activation of nucleus accumbens NMDA receptors differentially affects appetitive or aversive taste learning and memory. Front. Behav. Neurosci. 6:13. doi: 10.3389/fnbeh.2012. 00013

Copyright (C) 2012 Núñez-Jaramillo, Rangel-Hernández, Burgueño-Zúñiga and Miranda. This is an open-access article distributed under the terms of the Creative Commons Attribution Non Commercial License, which permits noncommercial use, distribution, and reproduction in other forums, provided the original authors and source are credited. 